\title{
A negação da pandemia: reflexões sobre a estratégia bolsonarista
}

\section{The pandemic denial: reflections about bolsonarist Strategy}

\author{
Gilberto Grassi Calila \\ (D) htttps://orcid.org/0000-0002-0479-7163
}

Resumo: Este artigo propõe refletir sobre a política do governo Jair Bolsonaro em relação à pandemia da covid-19. A hipótese central é que ela se baseia na intenção de atingir imunidade coletiva, estimulando a contaminação generalizada. Para atingir este objetivo, minimizou a gravidade da pandemia, estimulou comportamentos inadequados e disseminou informações inverídicas. Considera que os meses de março e abril foram decisivos na definição da estratégia do governo brasileiro e avalia os resultados que produziu.

Palavras-chave: Coronavírus. Pandemia. Covid-19. Governo Bolsonaro.

\begin{abstract}
This article proposes to reflect about the Jair Bolsonaro government politic concerning to the covid-19 pandemic. The central hypothesis is that it's intention to reach collective immunity. For this, the government stimulates widespread contamination. To achieve that goal he has been minimized the severity of the pandemic, and has been stimulating inappropriate behaviors, disseminating untrue information. This paper considers that the months of March and April were decisive in defining the strategy of the Brazilian government, and evaluates the results it has been produced.
\end{abstract}

Keywords: Coronavirus. Pandemic. Covid-19. Bolsonaro's government. 


\section{Apresentação}

ito meses depois de registrados os primeiros casos da covid-19, o Brasil está entre os países com os piores indicadores relativos a óbitos e contaminações. ${ }^{1}$ Em uma proposição crítica bastante difundida, afirma-se que essa situação seria resultado da falta de estratégia por parte do governo brasileiro. Nossa hipótese é que, ao contrário, a terrível situação em que o país se encontra é resultado de uma estratégia bem definida, coerente e sistematicamente aplicada por parte do governo Jair Bolsonaro, que, orientando-se pela perspectiva de atingir rapidamente a imunização coletiva (ou “imunidade de rebanho"), se utilizou de distintos instrumentos para estimular a intensificação da contaminação, recorrendo para tanto à disseminação de dados incorretos ou mesmo inteiramente falsos e à demonstração exemplar de comportamentos propícios à contaminação. Nesta perspectiva, entendemos que integram essa estratégia a desqualificação da pandemia ("histeria", "história mal contada”, "gripezinha”, "neurose”), o estímulo a atitudes que induzem à aceleração do ritmo de contaminação (aglomeração, uso incorreto da máscara, defesa da abertura de academias, salões de beleza e escolas) e a propagação de falsas soluções, em especial com anúncio enganoso de medicamentos comprovadamente ineficazes.

\section{Primeiras reações ao novo coronavírus no mundo}

Nas primeiras semanas de 2020, quando começaram a circular as informações sobre o novo coronavírus, posteriormente batizado

\footnotetext{
Tomamos como referência os dados de 17 de outubro de 2020, data de fechamento da Semana Epidemiológica 42, a 33a semana de vigência da pandemia no Brasil, considerando-se a data de registro do primeiro caso (25/2). Até então, levando-se em consideração apenas os dados oficiais, o Brasil é o sexto país com maior número de mortes por milhão de habitantes (com 721 óbitos por milhão, com uma letalidade mais de cinco vezes superior à média mundial, estando atrás apenas de San Marino, Peru, Bélgica, Andorra e Espanha). É ainda o $12^{\circ}$ em número de casos por milhão de habitantes, com 24.527. Em contrapartida, registra apenas 3,4 testes realizados por resultado positivo, muito abaixo da recomendação da OMS, que estabelece vinte testes por positivo como patamar mínimo para um efetivo controle.
} 
como covid-19, existiam muitas dúvidas e nenhuma certeza. Além das dificuldades inerentes ao estágio inicial de desenvolvimento de uma nova epidemia, ${ }^{2}$ havia muita desconfiança quanto à possível omissão de dados por parte do governo chinês. Foi nesse contexto que ganhou força a especulação de que o número total de contaminados seria muitas vezes superior ao divulgado pelo governo chinês, do que decorria a suposição de que o índice de letalidade real seria bastante baixo, dado que aquele país registrava pouco mais de 3 mil mortes e supunha-se que pudessem haver alguns milhões de contaminados. É nesse contexto que diversos governantes optaram em um primeiro momento por descartar a adoção de medidas rigorosas de contenção da epidemia, acreditando que poderiam chegar rapidamente a um patamar de contaminação que garantisse a imunidade coletiva. A despeito de suas implicações éticas, essa parecia uma alternativa politicamente sustentável para esses governantes, visando preservar os interesses da acumulação capitalista e impedindo um agravamento ainda maior da crise mundial do capital já então bastante intensa.

É importante para nosso argumento recuperar aquele momento inicial. Não é nossa intenção naturalizar nem tratar como aceitável aquela opção, mas situar que em um primeiro momento o caminho proposto por Bolsonaro era compartilhado por governos de inúmeros países, como Estados Unidos, Reino Unido, Itália, Holanda e Bélgica. O grande marco de difusão dessa perspectiva deu-se com o lançamento da campanha midiática Milano no si ferma, ${ }^{3}$ em 27 de fevereiro. A campanha propunha que se deveria manter a vida normal, minimizando a relevância da epidemia. Até aquele momento, a Itália registrava 655 casos e dezessete óbitos. ${ }^{4} \mathrm{~A}$

2 O Organização Mundial da Saúde declarou situação de pandemia apenas no dia 13 de março, portanto até então o novo coronavírus era abordado como epidemia, ainda que já estivesse avançando em inúmeros países.

3 Disponível em: https://www.youtube.com/watch?v=GrONsrz7W3s. Acesso em: 18 out. 2020.

4 Esses dados foram extraídos do wordometers, assim como os demais mencionados neste parágrafo. Disponível em: https://www.worldometers.info/coronavirus/country/italy/. Acesso em: 18 out, 2020. 
campanha foi imediatamente replicada nas principais cidades italianas, como Nápoles (29/2), ${ }^{5}$ Roma $(2 / 3)^{6}$ e Turim (5/5), ${ }^{7}$ e também em Bérgamo $(2 / 3),{ }^{8}$ que seria a cidade italiana mais atingida pela pandemia. Em todos os casos, os vídeos de lançamento da campanha foram produzidos em conjunto pelas câmeras de comércio e governos locais, argumentavam que as cidades não podiam parar e convidavam os turistas para que fossem desfrutá-las. Dois meses depois, no final de abril, o país já contabilizava 205.449 casos (um número reconhecidamente subdimensionado, pois até então apenas os casos mais graves eram testados) e 28.036 óbitos, tendo atingido o pico, com 921 óbitos em um dia, em 27 de março. No final de março, já tendo atingido 12.466 óbitos, a Itália concentrava $27,8 \%$ do total de mortos pela covid-19 em todo o mundo, mesmo não chegando a $1 \%$ da população mundial. A enorme dimensão da tragédia italiana, que já era claramente perceptível na terceira semana de março, sendo nitidamente decorrente das políticas negacionistas veiculadas desde o final de fevereiro, impulsionou radical mudança de perspectiva da maior parte dos governos do mundo, com o abandono da intenção de perseguir a imunidade coletiva e a adoção de políticas de contenção, com distintos graus de radicalidade. No caso italiano, as políticas foram rigorosas a ponto de terem logrado que ao longo de todo o mês de junho, com testagem muito ampliada, fossem registrados apenas 7.781 novos casos (uma média de menos de 260 por dia) e 588 óbitos (menos de vinte por dia).

Em 11 de março, a Organização Mundial da Saúde (OMS) declarou formalmente situação de pandemia mundial. Naquele momento, de forma simultânea, verificava-se rápido crescimento do número de casos e óbitos em diversos países, como Espanha, Alemanha, Estados Unidos, Irã e Coreia do Sul. Ainda não estava clara a letalidade real da covid-19 - que posteriormente, em inúmeros estudos de incidência

\footnotetext{
Disponível em: https://www.youtube.com/watch?v=EpKEuRHm9Sg. Acesso em: 18 out. 2020. Disponível em: https://www.youtube.com/watch?v=eBjPInpWwnM. Acesso em: 18 out. 2020. Disponível em: https://www.youtube.com/watch?v=5KvAKj5cXr8. Acesso em: 18 out. 2020.

Disponível em: https://www.youtube.com/watch?v=4zOZN9E_GQI. Acesso em: 18 out. 2020.
} 
realizados em países como Estados Unidos, Itália, Espanha, França e Suécia, seria estabelecida em patamares entre 0,7\% e 1\% do total de contaminados -, mas já era evidente que a letalidade era bem maior do que o inicialmente imaginado pelos defensores da busca de imunização coletiva via contaminação.

Nos Estados Unidos, o presidente Donald Trump politizou a situação desde o princípio, qualificando a covid-19 como "vírus chinês" e minimizando sua importância. Frente ao agravamento da situação, em discurso de 13 de março declarou estado de emergência e liberou vultuosos recursos para o enfrentamento da pandemia. Ainda assim, seguiria proferindo manifestações contraditórias e em momento algum propôs uma política nacional de contenção, restando apenas políticas regionalizadas por parte dos governos estaduais. ${ }^{9}$ A ausência de uma política nacional de contenção e a fragmentação das iniciativas — tal como no Brasil —, foram decisivas para o agravamento da situação do país.

Na segunda quinzena de março, a quase totalidade dos governos que haviam recusado medidas mais intensas de isolamento social e que de alguma forma apostaram na possibilidade de superar a pandemia através da imunidade coletiva produzida pela ampla contaminação mudou radicalmente suas políticas, a começar pela Itália e passando por países como Bélgica, Holanda e Espanha. ${ }^{10}$ No Reino Unido, depois de duas semanas de pronunciamentos contraditórios, finalmente em 23 de março

9 “Trump declara emergência nacional devido ao coronavírus". Deutsche Welle Brasil, 13 mar. 2020. Disponível em: https://www.dw.com/pt-br/trump-declara-emerg\%C3\%AAncia-nacional-devido-ao-coronav\%C3\%ADrus/a-52767985, Acesso em: 18 out. 2020.

10 A principal exceção, no contexto europeu, foi a Suécia, que, sob o comando do epidemiologista Anders Tegnell, manteve-se na perspectiva de busca pela imunização coletiva, recusando-se à adoção de políticas oficiais voltadas à promoção do isolamento social. Nesse contexto, apesar do isolamento voluntário de parte significativa da população, o país tinha em 17/10/2020 uma das maiores taxas de letalidade do mundo (585 mortes por milhão de habitantes), entre cinco e doze vezes maior que seus vizinhos nórdicos Dinamarca (117), Finlândia (63) e Noruega (51). Ainda assim, permanecia com número de casos ativos superior ao daqueles países. Disponível em: https://www.worldometers.info/coronavirus/. Acesso em: 18 out. 2020. 
Boris Johnson se manifestou reconhecendo a gravidade da situação e decretando três semanas de isolamento social estrito. ${ }^{11}$

Ainda no final de março foi divulgado o mais amplo estudo já realizado até então, produzido pelo Imperial College of London, que projetava o número de contaminações, óbitos e hospitalizações em 202 países, considerando diversos cenários, desde a supressão precoce (que implicava medidas rigorosas de isolamento social para o conjunto da população antes que se atingisse $0,2 \%$ da população contaminada) até o cenário oposto, no qual não seriam tomadas medidas de contenção, e incluindo cenários intermediários (como supressão tardia, estabelecida já a partir de patamar mais elevado, e supressão seletiva, que implicaria isolar apenas a parcela da população tida como mais vulnerável). ${ }^{12}$ Esse estudo teve impacto em diversos países e estimulou a adoção de medidas mais rigorosas de contenção em muitos deles. Para o Brasil, o estudo previa, no melhor cenário (com supressão precoce), 44.212 óbitos, e no pior (sem medidas de mitigação), 1.152.283 óbitos. Um dos cenários intermediários (isolamento social, sem medidas de supressão, mas com reforço no distanciamento de idosos) projetava para o país 529.779 óbitos, de 120 milhões de contaminados, e mais de 3 milhões de hospitalizados (dos quais mais de 700 mil em UTI). Os resultados do estudo mostravam não apenas os trágicos resultados que se poderia prever caso não fossem tomadas medidas, como impugnava definitivamente qualquer embasamento científico à proposta de isolamento seletivo - defendido por Bolsonaro sob a designação excêntrica de "isolamento vertical".

Ainda entre os meses de março e abril, outros dois fatores reforçavam a argumentação dos que entendiam que era necessária uma rigorosa

11 "Boris Johnson, da despreocupação com o coronavírus à hospitalização". O Estado de Minas, 14 abr. 2020. Disponível em: https://www.em.com.br/app/noticia/internacional/2020/04/13/ interna_internacional,1137991/boris-johnson-da-despreocupacao-com-o-coronavirus-a-hospitalizacao.shtml. Acesso em: 18 out, 2020.

12 Os dados completos e detalhados estão disponíveis em: https://www.imperial.ac.uk/media/ imperial-college/medicine/sph/ide/gida-fellowships/Imperial-College-COVID19-Global-unmitigated-mitigated-suppression-scenarios.xlsx. Acesso em: 18 out. 2020. 
política de contenção: os primeiros registros de casos de reinfecção, que produziam incerteza ainda maior quanto à viabilidade de obter imunização por meio de ampla contaminação, e a crescente percepção de que mesmo entre os pacientes "recuperados", uma parte era vítima de efeitos colaterais os mais distintos, como redução da capacidade pulmonar, problemas auditivos, desenvolvimento de diabetes, perturbações no sistema nervoso e lesão cerebral, o que ensejava a percepção de que a covid-19 produzia uma doença sistêmica, e não exclusivamente pulmonar, como se imaginou a princípio. ${ }^{13}$

\section{Os primeiros meses da pandemia no Brasil: março e abril}

O Brasil teve o primeiro caso confirmado de covid-19 no dia 25 de fevereiro, e o primeiro óbito três semanas depois, em 17 de março. As opções políticas tomadas nos primeiros dias de março foram decisivas e determinaram os rumos da pandemia no país, que se consolidaram com o pronunciamento nacional de Jair Bolsonaro em 24 de março, de conteúdo explicitamente negacionista. As primeiras medidas oficiais de contenção foram anunciadas no dia 13 de março - quando o país registrava ainda apenas 151 casos e, portanto, ainda tinha possibilidades de implantar um plano de contenção efetiva. Essas medidas determinavam o cancelamento de cruzeiros turísticos no país e a obrigatoriedade de quinze dias de isolamento a todos os passageiros que ingressassem no país vindos do exterior. ${ }^{14}$ Embora limitadas e insuficientes, eram medidas

13 "Covid-19 pode deixar sequelas no sistema nervoso central, diz estudo". CNN Brasil, 22 abr. 2020. Disponível em: https://www.cnnbrasil.com.br/saude/2020/04/22/covid-19-pode-deixar-sequelas-no-sistema-nervoso-central-diz-estudo. Acesso em: 18 out. 2020.

14 "Ministério da Saúde determina cancelamento de cruzeiros turísticos no país". G1, 13 mar. 2020. Disponível em: https://g1.globo.com/turismo-e-viagem/noticia/2020/03/13/ministerio-da-saude-determina-cancelamento-de-cruzeiros-turisticos-no-pais.ghtml. Acesso em: 18 out. 2020. Conforme é relatado no livro do ex-ministro Henrique Mandetta, essa não foi a primeira medida legal relacionada à covid-19, pois antes disso havia sido aprovada uma lei que tornava possível a imposição de quarentena em determinadas situações, com o objetivo específico de 
que expressavam a intenção de produzir alguma mitigação, buscando ao menos reduzir o ritmo de contaminação. A medida, no entanto, foi revogada no mesmo dia. Conforme o relato do ex-ministro Henrique Mandetta (2020, p. 83-84):

Wanderson de Oliveira redigiu então um boletim determinando a proibição de partida e chegada de cruzeiros na costa brasileira. Era consenso entre nós que seria uma irresponsabilidade manter o fluxo de turistas num momento daqueles. Se estávamos orientando fechamentos de bares e restaurantes, o mesmo princípio tinha que ser adotado para navios de cruzeiro. Essa nem era uma medida excepcional do Brasil, todo o planeta já tinha adotado esse bloqueio. $\mathrm{O}$ Wanderson preparou o boletim, me mostrou, e eu disse: "Vai em frente, pode bloquear".

Menos de duas horas depois da publicação do documento começou uma gritaria promovida pelo lobby do setor de turismo, reclamando dos prejuízos que a medida traria para os operadores de cruzeiros. O presidente Jair Bolsonaro imediatamente me ligou querendo explicações e pedindo que eu cancelasse o boletim. [...]. O Ministério da Saúde já enfrentava muitos desafios, e achei que não seria prudente entrar em rota de colisão com o presidente e seus ministros tão cedo.

$\mathrm{O}$ relato do ex-ministro Mandetta evidencia que, embora tenham ocorrido conflitos anteriormente, foi a partir daquele momento que a posição negacionista de Bolsonaro se consolidou, a ponto de sabotar abertamente as medidas de contenção e o trabalho desenvolvido no Ministério da Saúde:

Foi a partir daquele domingo, dia 15, que duas mensagens começaram a circular juntas, uma se contrapondo à outra. O Ministério da Saúde indicava um caminho, e o presidente enviava uma mensagem no sentido oposto, a

viabilizar o resgate dos brasileiros que estavam na China e garantir que ficassem confinados até que pudessem ser liberados com segurança. $\mathrm{O}$ resgate foi realizado, e a quarentena dos resgatados encerrou-se em 23 de fevereiro, dois dias antes do registro do primeiro caso no país. 
de não respeitar as orientações do seu próprio ministério. Antes já havia essa resistência, mas não era pública (Mandetta, 2020, p. 32). ${ }^{15}$

O infectologista Júlio Croda, que ocupava a Diretoria do Departamento de Imunização e Doenças Transmissíveis do Ministério da Saúde, foi o primeiro a se demitir, ainda em março, afirmando: "Não quis ser responsável por essa recomendação equivocada contra o isolamento social e por um número importante de óbitos. ${ }^{16}$ Em entrevista posterior, Croda apontou a polêmica e censura em torno do Boletim Epidemiológico 5, de 14 de março de 2020, como estopim da crise. Segundo ele, apesar de já ter recebido análises e projeções que justificariam a tomada de medidas rigorosas, em conjunto com a Casa Civil, Bolsonaro censurou as medidas de contenção propostas no Boletim. ${ }^{17}$ No dia 18 de março, um novo protocolo indicava que a partir de então seriam testados apenas os pacientes em estado grave, uma decisão que liquidava definitivamente qualquer possibilidade de controle sobre a pandemia e que curiosamente não é mencionada no livro de Mandetta.

A estratégia de Bolsonaro já estava traçada, mas seria mais bem explicitada em seu pronunciamento à nação no dia 24 de março:

Nosso ministro da Saúde reuniu-se com quase todos os secretários de Saúde dos estados para que o planejamento estratégico de combate ao vírus fosse construído e, desde então, o doutor Henrique Mandetta vem desempenhando um excelente trabalho de esclarecimento e preparação do SUS para atendimento de possíveis vítimas. Mas o que tínhamos que conter naquele momento era o pânico, a histeria. E, ao mesmo tempo, traçar a estratégia para salvar vidas e evitar o desemprego em massa. Assim fizemos, quase contra tudo e contra todos.

15 Recorremos aqui a aspectos específicos do relato de Mandetta sem, no entanto, endossar sua interpretação de conjunto, como indicaremos na próxima seção.

16 “Infovid 12: os primeiros momentos da pandemia”. Instituto Questão de Ciência, 19 ago. 2020. Disponível em: https://www.youtube.com/watch?v=kMFj7hPwOyU\&ab_channel=iqciencia. Acesso em: 18 out. 2020.

17 Disponível em: https://www.youtube.com/watch?v=kMFj7hPwOyU. Acesso em: 18 out. 2020. 
Grande parte dos meios de comunicação foram [sic] na contramão. Espalharam [sic] exatamente a sensação de pavor, tendo como carro-chefe o anúncio de um grande número de vítimas na Itália, um país com grande número de idosos e com um clima totalmente diferente do nosso. Um cenário perfeito, potencializado pela mídia, para que uma verdadeira histeria se espalhasse pelo nosso país. [...]

O vírus chegou, está sendo enfrentado por nós e brevemente passará. Nossa vida tem que continuar. Os empregos devem ser mantidos.

O sustento das famílias deve ser preservado. Devemos, sim, voltar à normalidade. Algumas poucas autoridades estaduais e municipais devem abandonar o conceito de terra arrasada, como proibição de transporte, fechamento de comércio e confinamento em massa. 0 que se passa no mundo tem mostrado que o grupo de risco é o das pessoas acima dos 60 anos. Então, por que fechar escolas? Raros são os casos fatais de pessoas sãs, com menos de 40 anos de idade. $90 \%$ de nós não teremos qualquer manifestação caso se contamine. Devemos, sim, é ter extrema preocupação em não transmitir o vírus para os outros, em especial aos nossos queridos pais e avós. Respeitando as orientações do Ministério da Saúde.

No meu caso particular, pelo meu histórico de atleta, caso fosse contaminado pelo vírus, não precisaria me preocupar, nada sentiria ou seria, quando muito, acometido de uma gripezinha ou resfriadinho, como bem disse aquele conhecido médico daquela conhecida televisão.

Enquanto estou falando, o mundo busca um tratamento para a doença. O FDA americano e o Hospital Albert Einsten, em São Paulo, buscam a comprovação da eficácia da cloroquina no tratamento do covid-19. Nosso governo tem recebido notícias positivas sobre este remédio fabricado no Brasil e largamente utilizado no combate à malária, lúpus e artrite. [...]

Sem pânico ou histeria, como venho falando desde o início, venceremos o vírus e nos orgulharemos de estar vivendo neste novo Brasil, que tem tudo, sim, para ser uma grande nação. Estamos juntos, cada vez mais unidos, Deus abençoe nossa pátria querida. ${ }^{18}$

18 “'Gripezinha': leia o pronunciamento do presidente Jair Bolsonaro na íntegra”. UOL, 24 mar. 2020. Disponível em: https://noticias.uol.com.br/politica/ultimas-noticias/2020/03/24/leia-o-pronunciamento-do-presidente-jair-bolsonaro-na-integra.htm. Acesso em: 18 out. 2020. Grifos meus. 
A extensa citação e os inúmeros grifos justificam-se pelo fato de que este pronunciamento reúne e articula os principais eixos discursivos que viriam a fundamentar o negacionismo propagado por Bolsonaro desde então. Ainda que em um primeiro momento a maior parte da população tenha sido contrária ao pronunciamento, ele permitiu reforçar os laços com seus seguidores mais próximos, o que seria fundamental para garantir o fracasso das políticas de contenção ao longo dos meses seguintes.

Grande parte dos argumentos utilizados para minimizar os riscos e subdimensionar a pandemia já estava presente, incluindo-se a desqualificação das medidas necessárias para a contenção e a propagação de falsas ilusões com medicamentos sem eficiência comprovada. Como registra o Monitor do Debate Político no Meio Digital, "no Facebook, o pico no número de novos seguidores nas 72 horas que se seguiram ao pronunciamento do presidente defendendo relaxamento do distanciamento social foi o maior em todo o período analisado, duas vezes maior do que o segundo pico. No Instagram, no Twitter e no YouTube, o saldo no número de seguidores também foi positivo". ${ }^{19}$ Bolsonaro falava para seu público mais fiel, não apenas para reforçar sua adesão, mas também porque suas atitudes seriam determinantes para sabotar as políticas de contenção que já vinham sendo desenvolvidas no âmbito dos estados.

Os temas presentes no pronunciamento oficial, que já se expressavam anteriormente, seriam repetidos inúmeras vezes desde então, produzindo uma abordagem centrada na minimização da pandemia, na desqualificação das medidas de contenção, na naturalização da morte e na suposição de uma espécie de teoria da conspiração, como se vê nas afirmações selecionadas no Quadro 1.

19 Postagem do Monitor do Debate Político no Meio Digital, 4 abr. 2020. Disponível em: https:// www.facebook.com/monitordodebatepolitico/. Acesso em: 18 out. 2020. 
Quadro 1. Declarações de Jair Bolsonaro em março e abril

\begin{tabular}{|l|c|c|c|}
\hline \multicolumn{1}{|c|}{ Declaração } & Data & $\begin{array}{c}\text { Número } \\
\text { de casos } \\
\text { na data }\end{array}$ & $\begin{array}{c}\text { Número } \\
\text { de óbitos } \\
\text { na data }\end{array}$ \\
\hline $\begin{array}{l}\text { “O que está errado é a histeria, como se fosse o fim do } \\
\text { mundo. Uma nação como o Brasil só estará livre quando } \\
\text { certo número de pessoas for infectado e criar anticorpos” }\end{array}$ & $17 / 3$ & 346 & 1 \\
\hline $\begin{array}{l}\text { “Não vai ser uma gripezinha que vai me derrubar, tá o.k.?” } \\
\text { “O povo foi enganado esse tempo todo sobre o vírus” }\end{array}$ & $20 / 3$ & 957 & 11 \\
\hline $\begin{array}{l}\text { “Se o vírus pegar em mim, não vou sentir quase nada” } \\
\text { “Está começando a ir embora essa questão do vírus” }\end{array}$ & $30 / 3$ & 2.902 & 77 \\
\hline $\begin{array}{l}\text { “Eu não sou coveiro, tá certo?” } \\
\text { “E daí? Lamento. Quer que eu faça o quê? Eu sou Messias, }\end{array}$ & $28 / 4$ & 22.192 & 1.223 \\
\hline mas não faço milagre” & $20 / 4$ & 40.743 & 2.587 \\
\hline
\end{tabular}

As manifestações de Bolsonaro eram amplificadas pela divulgação de mensagens nas redes sociais por intermédio das estruturas de propaganda bolsonaristas comumente designadas como “Gabinete do Ódio". É difícil estabelecer com precisão a dimensão e o alcance dessas estruturas, já que os disparos ocorrem em grupos fechados e de forma privada. Ainda assim, é possível identificar seu sentido geral, com relatos que em um primeiro momento eram voltados para a minimização dos riscos, sustentando que a pandemia não se desenvolveria no Brasil e que haveria poucos casos e reduzido número de vítimas, como indicam os resultados de estudo desenvolvido conjuntamente pelo projeto Eleições sem Fake e pelo Monitor do Debate Político no Meio Digital, que analisou 2.108 áudios que circularam entre os dias 24 e 28 de março, em 522 grupos públicos de Whatsapp, com a participação de mais de 18 mil usuários ativos, comprovando a enorme circulação de fake news:

Entre os 20 áudios com maior circulação, cinco negam a gravidade do covid-19 (Coronavírus) - quatro deles estão entre os 10 mais compartilhados. Segundo estes áudios, com supostos depoimentos de médicos e testemunhas, as CTIs estão vazias, as funerárias estão sem corpos e os 
mortos por acidente estão sendo contabilizados como mortos pelo vírus. Esses cinco áudios são responsáveis por 35\% dos compartilhamentos totais da amostra analisada. ${ }^{20}$

A mais compartilhada dentre elas sustentava que os moradores de rua eram imunes à contaminação, o que atestaria a desnecessidade de medidas de isolamento. ${ }^{21}$ Esse conjunto de mensagens sustentava, na senda do discurso presidencial, que a pandemia não avançaria no Brasil devido ao clima quente, ao predomínio de jovens e à baixa densidade demográfica do país. Uma das mensagens mais disseminadas naquele momento sustentava que o vírus não resistiria a temperaturas superiores a 26 graus, ${ }^{22}$ mensagem que circulou especialmente nas regiões mais quentes do país e que estiveram entre as mais intensamente atingidas nos primeiros meses da pandemia no país, como Amazonas, Pará, Maranhão, Pernambuco, Ceará e Rio de Janeiro.

Com o crescimento do número de óbitos, que dobrava a cada semana ao longo do mês de abril, o eixo do negacionismo passou a se concentrar no anúncio de medicamentos supostamente milagrosos (em especial, a cloroquina) e na contestação da veracidade dos registros. Ainda em março, disseminou-se o relato fantasioso que afirmava que "o primo do porteiro do prédio morreu porque foi trocar o pneu do caminhão e o pneu estourou

20 “Áudios em grupos de Watsapp negam mortes por coronavírus". Eleições sem Fake / Monitor do Debate Político no Meio Digital, 29 mar. 2020. Disponível em: https://drive.google.com/ file/d/1LAD2eAaehCtFFzUw5iUbPuvUABjA97Na/view?fbclid=IwAR3f7kXrlq6FQXVSiGULMM_4yB3kN5EYRAZw310UlbNDcNJ9y7V5GvaonqI. Acesso em: 18 out. 2020.

21 A permanência de relatos fantasiosos como este é atestada pelo fato de que foi repetido mais de seis meses depois por Celso Russomano, candidato bolsonarista à prefeitura de São Paulo, que citou exatamente a alegada "resistência" dos moradores de rua como justificativa de sua oposição a medidas de isolamento social. "Russomano insiste em resistência de moradores de rua à covid-19: 'Imunes'”. Disponível em: https://www.metropoles.com/brasil/russomanno-insiste-em-resistencia-de-moradores-de-rua-a-covid-19-imunes. Acesso em: 18 out. 2020.

22 "É \#fake que o vírus não resiste ao calor e a temperatura de 26 ou 27 graus". G1, 18 mar. 2020. Disponível em: https://g1.globo.com/fato-ou-fake/noticia/2020/03/18/e-fake-que-novo-coronavirus-nao-resiste-ao-calor-e-a-temperatura-de-26oc-ou-27oc.ghtml. Acesso em: 18 out. 2020. 
no rosto dele. Receberam o atestado de óbito como se fosse covid-19”. ${ }^{23}$ Como é recorrente na produção de fake news, a mentira era disseminada em diversas versões, com variações e adaptações regionais. É importante observar que o auge de circulação de mensagens desse tipo (entre o final de março e o final de abril) corresponde ao período em que no âmbito da maioria dos estados eram tomadas medidas de mitigação. O Monitor do Debate Político no Meio Digital confirma a correlação entre apoio a Bolsonaro e relaxamento dos cuidados, registrando em Nota Técnica que "o relaxamento do distanciamento social posterior ao pronunciamento foi mais forte entre apoiadores do presidente”. ${ }^{4}$ Portanto, parece-nos inegável que a posição assumida por Bolsonaro levou parcela da população a recusar os cuidados, o que teria sido decisivo para que tais medidas não tenham produzido os resultados esperados.

\section{Da demissão de Mandetta à normalização da pandemia}

Desde meados de março, tornava-se mais visível a contraposição entre Mandetta e Bolsonaro. Também governadores de estados importantes, como Rio de Janeiro e São Paulo, defendiam posições próximas às de Mandetta, o que fortaleceu a impressão de que a política sustentada por eles era antagônica à proposta por Bolsonaro. Nosso entendimento, no entanto, é que não há antagonismo entre ambas as posições, na medida em que nenhum deles orientava-se pela perspectiva de atingir uma contenção efetiva. Nesse confronto, os críticos de Bolsonaro limitavam sua proposta

23 “Fake news 'do borracheiro' é usada para desacreditar números do coronavírus”. Clicrbs, 29 mar. 2020. Disponível em: https://gauchazh.clicrbs.com.br/coronavirus-servico/noticia/2020/03/ fake-news-do-borracheiro-e-usada-para-desacreditar-numeros-do-coronavirus-ck8dibh7y02tz01091mc4j6s4.html. Acesso em: 17 out. 2020.

24 "Nota Técnica \#09 - Eleitores e apoiadores de Bolsonaro respeitam menos a quarentena". Monitor do Debate Político no Meio Digital, 6 maio 2020. Disponível em: https://www.monitordigital.org/2020/05/06/nota-tecnica-09/?fbclid=IwAR2F3_TkJ-tjj7UYpL24wpBstUtXlZ-DHXwO8d-iiUCfpGFmQP7yAVgdOqE. Acesso em: 18 out. 2020. 
ao estabelecimento de medidas de mitigação, que fossem suficientes para administrar a pandemia dentro dos limites da capacidade de atendimento do sistema de saúde. Portanto, em alguma medida compartilhavam com Bolsonaro o pressuposto de que era impossível conter a transmissão (ao contrário do que propunham e efetivaram governos de diversos países do mundo, incluindo a China, e que permanecem com menos de dez óbitos por milhão de habitantes). É inegável que o estabelecimento de lockdown nacional constitui elemento central de uma política de contenção efetiva, e portanto é sintomático que em seu livro Mandetta use uma única vez a expressão lockdown e que lhe atribua conotação negativa, associado a "exagero", ao relatar uma cobrança recebida de Bolsonaro: "Ele rebateu dizendo que havia lugares que não tinham nenhum caso e que estavam em lockdown. De fato, algumas cidades erravam por excesso" (Mandetta, 2020 , p. 117). Seu relato omite que os países que realizaram os lockdowns mais bem-sucedidos adotaram medidas em âmbito nacional, aplicadas simultaneamente em regiões com diferentes estágios de propagação. A condução de Bolsonaro inviabilizou a adoção de medidas com essa perspectiva, e é por isso que o efeito das medidas tomadas regionalmente que na imensa maioria dos casos, ao contrário do que sugere Mandetta, não configuraram lockdowns - foi muito limitado.

Ao conseguir apresentar Mandetta e os governadores que lhe faziam oposição como se estes se situassem no polo oposto, Bolsonaro conseguiu eliminar do debate público ou isolar inteiramente as propostas que de forma mais rigorosa indicavam a necessidade de medidas mais amplas e que fossem estabelecidas em âmbito nacional. Da mesma forma que fez desaparecer a distinção entre a perspectiva de mitigação (que era compartilhada pelos seus críticos mais conhecidos) e a perspectiva de contenção (que demandaria o estabelecimento de lockdown nacional). É sintomático que Mandetta tenha usado o termo lockdown para designar políticas muito mais limitadas de mitigação, produzindo uma confusão que enseja a falsa ideia de que o Brasil chegou a ter um lockdown, e não uma quarentena desigual, fragmentada 
e sabotada pelos seguidores do presidente), o que constitui um inegável êxito do presidente e serviu para justificar e legitimar a administração da pandemia de uma forma que permitiu e normalizou a manutenção de um patamar semanal superior a 5 mil mortes oficialmente registradas por dezenove semanas. ${ }^{25}$

Entre a expressão pública da divergência entre Bolsonaro e Mandetta e sua demissão, em 16 de abril, passaram-se trinta dias. A questão que se coloca então é: por que um presidente autoritário e centralizador manteve um ministro que explicitava cada dia mais sua divergência com as afirmações e o comportamento do presidente? No nosso entendimento, a permanência de Mandetta durante esse período era necessária para o êxito da estratégia de Bolsonaro, na medida em que estabelecer algumas medidas de mitigação era imprescindível para impedir um colapso do sistema de saúde. Assim, embora publicamente Bolsonaro combatesse tais medidas, seu projeto de normalização da pandemia necessitava que parte da população mantivesse alguns cuidados, e para tanto foi funcional manter Mandetta no Ministério até que o risco de colapso geral do sistema de saúde estivesse mais distante. Paradoxalmente, a estratégia negacionista de Bolsonaro só poderia ter êxito se, ao menos em um primeiro momento, suas proposições não fossem integralmente seguidas, pois se o fossem, produziriam um desastre de forma tão rápida e intensa que provavelmente teria produzido um repúdio incontrolável. Entre 16 de março e 16 de abril, o número de casos registrados aumentou mais de 130 vezes (de 234 para 30.683), e o país passou de zero para 1.947 óbitos. Esse crescimento estrondoso foi o suficiente para inviabilizar daí em diante a adoção de uma política de contenção (que, ademais, só seria efetiva se fosse assumida pelo próprio governo federal), mas não foi grande o bastante para produzir um colapso hospitalar e funerário generalizado.

25 Disponível em: https://www.conass.org.br/painelconasscovid19/. Acesso em: 18 out. 2020. 


\section{Considerações finais}

O desenvolvimento da tragédia brasileira de abril em diante ocorreu de acordo com o que fora planejado por Bolsonaro. Progressivamente, setores cada vez mais expressivos da população cansaram-se da adoção de medidas de proteção desgastantes e para muitos economicamente insustentáveis, e que lhes pareciam pouco efetivas. Os próprios governadores que expressavam posições distintas, quando não foram derrubados (como Wilson Witzel, no Rio de Janeiro), foram modificando suas posições e passaram a defender a reabertura econômica e uma progressiva normalização, mesmo em um contexto em que a pandemia seguia fora de controle. A militarização do Ministério da Saúde logrou oficializar uma política negacionista, que difunde medicamentos comprovadamente ineficazes, comemora o número de "recuperados" (omitindo as sequelas permanentes de parte deles), restringe gradativamente a testagem e consolida o ocultamento de parte significativa dos óbitos, registrando-os como síndrome respiratória aguda grave não especificada. ${ }^{26}$ Ao longo desse processo, repetiu sistematicamente afirmações insustentáveis ${ }^{27}$ e fez inúmeras aparições em público sem máscara e estimulando aglomerações. Bolsonaro conseguiu eliminar do horizonte a possibilidade de

26 De acordo com o Boletim Epidemiológico Especial 34, 28,1\% (57.292) do total de óbitos registrados por síndrome respiratória aguda grave até 6/10/2020 estava classificado na categoria "não especificada" Disponível em: https://portalarquivos2.saude.gov.br/images/pdf/2020/ October/08/Boletim-epidemiologico-COVID-34.pdf, p. 31. Acesso em: 18 out. 2020. Júlio Croda menciona que uma validação independente estabeleceu que mais de $95 \%$ desses óbitos é covid-19, ainda que não seja contabilizado como tal. "Infovid 12: os primeiros momentos da pandemia”. Instituto Questão de Ciência, 19 ago. 2020. Disponível em: https://www.youtube. com/watch?v=kMFj7hPwOyU\&ab_channel=iqciencia. Acesso em: 18 out. 2020.

27 De acordo com a agência de checagem Aos Fatos, até 15 de outubro, Jair Bolsonaro proferiu 684 afirmações falsas ou distorcidas tratando do coronavírus. Dentre elas, as mais recorrentes referem-se à afirmação de que o Supremo Tribunal Federal o teria impedido de agir (58 ocorrências), a de que o país só estará livre do vírus quando $70 \%$ da população tiver sido contaminada (34 ocorrências) e a de que a hidroxicloroquina é eficaz, ou que não tem sua eficácia desmentida por nenhum estudo (dezenove ocorrências). Disponível em: https://www. aosfatos.org/todas-as-declara\%C3\%A7\%C3\%B5es-de-bolsonaro/. Acesso em: 18 out. 2020. 
contenção efetiva, apresentou-se como preocupado com a economia e atribuiu a responsabilidade pela crise aos defensores do isolamento social (ainda que sua política tenha agravado a crise ao prolongar a vigência da pandemia) e colheu como resultado um índice crescente de aprovação popular. É certo que enquanto a pandemia estiver em curso, mantém-se um embate em torno das interpretações sobre a política adotada. Ainda assim, oito meses depois dos primeiros registros no país, a estratégia de Bolsonaro mostra-se exitosa, com um trágico saldo que se expressa nos índices que colocam o país entre os que tiveram mais óbitos e contaminações, tanto em termos absolutos (153.675 mil óbitos até 17/10/2020) como proporcionais à população (722 óbitos por milhão na mesma data).

\section{Referência}

MANDETTA, Luiz Henrique. Um paciente chamado Brasil: os bastidores da luta contra o coronavírus. Rio de Janeiro: Objetiva, 2020.

\section{Sobre o autor}

Gilberto Grassi Calil - Doutor em História Social. Estágio de Pós-Doutoramento na Universidade do Porto. Professor-associado do Curso de História e do Programa de Pós-Graduação em História.

E-mail: gilbertocalil@uol.com.br 